\title{
Cardiopulmonary bypass elicits a prominent innate immune response in children with congenital heart disease
}

\author{
Christian F. Stocker, MD, ${ }^{a}$ Lara S. Shekerdemian, MRCP, FRACP, MD, ${ }^{a}$ Kumar Visvanathan, MB BS, FRACP, PhD, ${ }^{\mathrm{b}, \mathrm{c}}$ \\ Narelle Skinner, Bsc, ${ }^{\text {b }}$ Christian P. Brizard, MD, ${ }^{d}$ John B. Carlin, BSc, PhD, Astat, ${ }^{\text {eff }}$ Steven B. Horton, BAppSc, CCP \\ (Aus), CCP (USA), ${ }^{g}$ and Daniel J. Penny, MD, FRCPI, ${ }^{\mathrm{h}}$ Parkville, Victoria, Australia
}

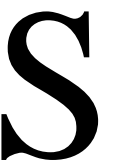
ystemic inflammatory response syndrome (SIRS) is common after operations for congenital heart disease (CHD). ${ }^{1}$ SIRS is characterized by release of proinflammatory cytokines, but the mechanisms initiating this cascade remain ill defined. Recent data from septic patients and a single study in adults undergoing heart surgery suggest that activation of the innate immune response might provide this early trigger. ${ }^{2,3}$ However, there are no other data that explore the contribution of the innate immune response in SIRS associated with cardiopulmonary bypass (CPB), specifically none in children. We have investigated, for the first time, the regulation of toll-like receptor 2 (TLR-2) and TLR-4 expression on peripheral blood monocytes of children with an inflammatory response after operations for CHD.

\section{Methods}

Nine children (median age, 6 months; weight, $5.6 \mathrm{~kg}$ ) undergoing surgical intervention for CHD were studied. They were the first cohort to be recruited for a prospective study of moderate hypothermic versus normothermic CPB, which was approved by our institutional ethics committee. Blood samples were taken for TLR-2 and TLR-4 and the cytokines tumor necrosis factor $\alpha$ (TNF- $\alpha$ ) and interleukin 6 (IL-6) at the following time points: before CPB (after anesthesia), after crossclamp removal, and at 4 , 24 , and 48 hours after separation from CPB. All children received methylprednisolone $(25 \mathrm{mg} / \mathrm{kg})$ after induction of anesthesia and underwent hemofiltration during bypass and modified ultrafiltration after separation from $\mathrm{CPB}$.

Plasma TNF- $\alpha$ and IL-6 concentrations were measured by means of capture enzyme-linked immunosorbent assay (Human TNF- $\alpha$ and IL-6 OptEIA; BD Pharmingen, San Diego, Calif).

\footnotetext{
From the Departments of Intensive Care, ${ }^{\mathrm{a}}$ Cardiac Surgery, ${ }^{\mathrm{d}}$ Perfusion, ${ }^{\mathrm{g}}$ and Cardiology, ${ }^{\text {h }}$ Royal Children's Hospital, Parkville, Victoria, Australia; the Staph and Strep Group ${ }^{\mathrm{b}}$ and the Epidemiology and Biostatistics Unit, ${ }^{\mathrm{e}}$ Murdoch Children's Research Institute, Parkville, Victoria, Australia; the Department of Medicine, ${ }^{\mathrm{c}}$ Royal Melbourne Hospital, Parkville, Victoria, Australia; and the Department of Pediatrics, ${ }^{f}$ University of Melbourne, Parkville, Victoria, Australia.

Received for publication Oct 29, 2003; revisions received Nov 18, 2003; accepted for publication Nov 24, 2003.

Address for reprints: Daniel J. Penny, MD, FRCPI, Department of Cardiology, Royal Children's Hospital, Flemington Rd, Parkville, Victoria 3052, Australia (E-mail: dan.penny@ rch.org.au).

J Thorac Cardiovasc Surg 2004;127:1523-5

$0022-5223 / \$ 30.00$

Copyright (C) 2004 by The American Association for Thoracic Surgery

doi:10.1016/j.jtcvs.2003.11.027
}

Cell-surface staining for TLR and CD14 was performed on whole blood according to published methods by using human monoclonal antibodies: anti-TLR-2 fluorescein isothiocyanate, anti-TLR-4 phycoerythrin (eBioscience, San Diego, Calif), and anti-CD14 peridinin chlorophyll protein (Becton Dickinson, San Diego, Calif). ${ }^{4}$ Eight thousand $\mathrm{CD} 14^{+}$cells were acquired for each sample; dead cells were gated out on a FACS Caliber flow cytometer (Becton Dickinson). TLR values were expressed as a ratio of the geometric mean fluorescence intensity to the matching isotype control for each sample.

Statistical analysis of changes over time used linear mixed models for longitudinal data fitted to log-transformed mean fluorescence intensity ratios (TLR values) and concentrations (IL-6 and TNF- $\alpha$ ). Results are summarized by using geometric mean values with $95 \%$ confidence intervals (CIs). Analysis was performed with the Stata package (Stata Statistical Software, Release 8.1; StatCorp, College Station, Tex).

\section{Results}

CPB time was 109 minutes (95\% CI, 91-186 minutes), and crossclamp duration was 66 minutes (95\% CI, 60-110 minutes). Figure 1 shows individual toll and cytokine data for each patient, and Table 1 provides geometric mean values at each time point. There was a clear increase in values after bypass for TLR-2 (log scale linear trend, $P=.008)$ and TLR-4 $(P<.001)$, fitting a line constrained to pass through the origin (ratio $=1$ ) at the pre-CPB point. There was also strong evidence of linear increase in $(\log )$ IL-6 value $(P<.001)$ but no change in TNF- $\alpha$ value $(P=.4)$. For TLR-4 and IL-6, there was further evidence for curvature in the pattern of change over time, reflecting a flattening out or possible reduction by 48 hours after bypass.

\section{Discussion}

For the first time, we have examined TLR expression in young children undergoing operations for CHD. Our study has demonstrated increased activation of the innate immune response in children after CPB, with specific upregulation of TLR-2 and TLR-4. There was a corresponding increase in IL-6 levels, which is one of the cytokines that is produced by stimulation of the TLRs. TNF- $\alpha$ levels were unchanged, possibly reflecting factors including the effects of steroids, hemofiltration, and ultrafiltration or perhaps supporting the suggestion that this cytokine does not contribute to CPB-induced SIRS.

The innate immune system plays a pivotal role in initiating first-line host defense to infection. This is dependent on recognition by TLRs of nonspecific proteins on invading pathogens; one 

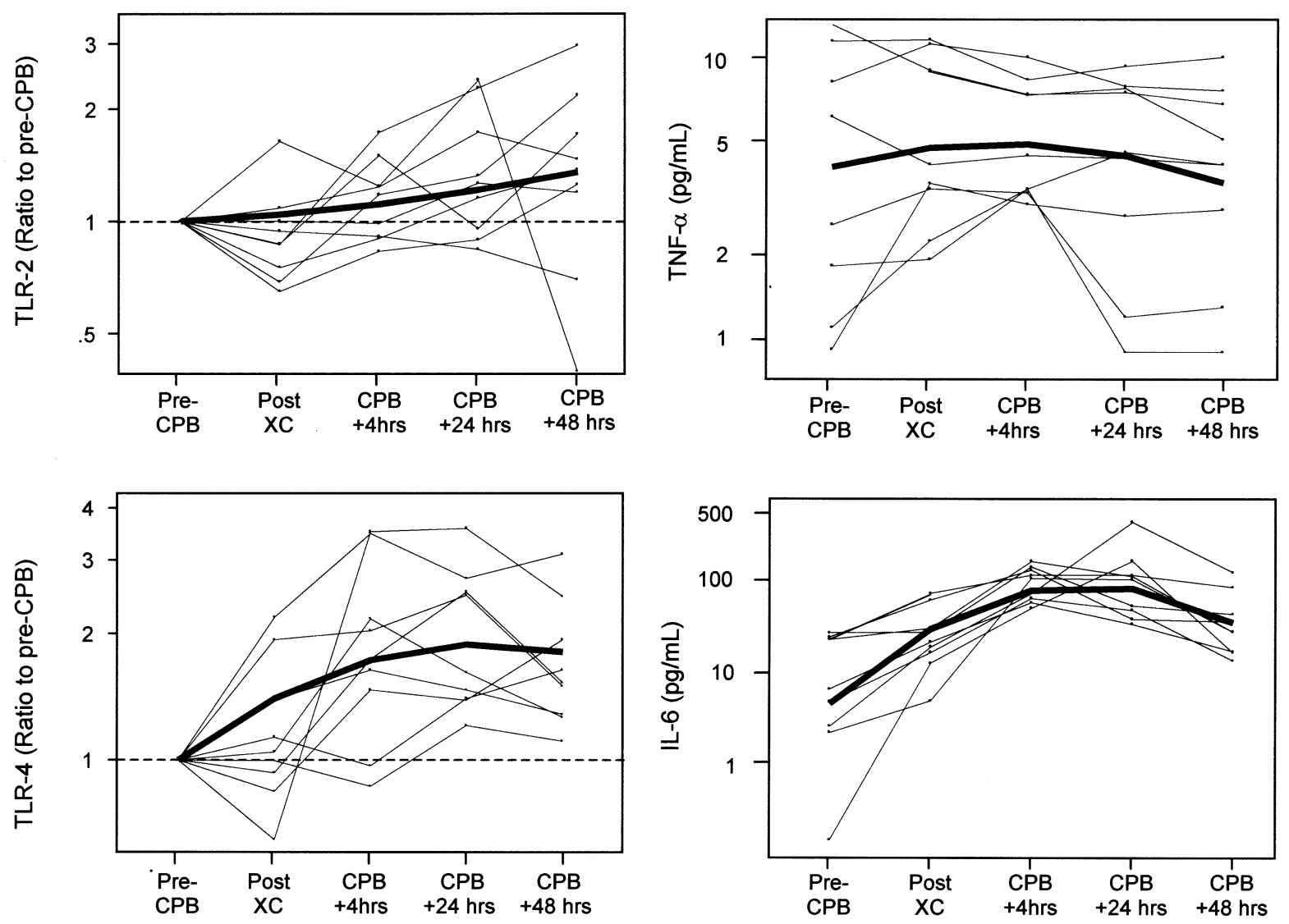

Figure 1. Individual toll and cytokine data are shown for each patient. CPB, Cardiopulmonary bypass; $X C$, crossclamp; TLR, toll-like receptor; TNF- $\alpha$, tumor necrosis factor $\alpha$; IL-6, interleukin 6.

TABLE 1. Geometric mean of MFI ratios (relative to control level at pre-CPB baseline) for (TLR-2 and TLR-4) and geometric mean of concentrations of IL- 6 and TNF- $\alpha$ at each time point, with $95 \%$ confidence intervals in parentheses

\begin{tabular}{|c|c|c|c|c|c|}
\hline & Before CPB & After XC & $\mathrm{CPB}+4 \mathrm{~h}$ & $\mathrm{CPB}+24 \mathrm{~h}$ & $\mathrm{CPB}+48 \mathrm{~h}$ \\
\hline TLR-2 & 1 & $\begin{array}{c}0.91 \\
(0.73-1.13)\end{array}$ & $\begin{array}{c}1.14 \\
(0.94-1.38)\end{array}$ & $\begin{array}{c}1.33 \\
(0.99-1.80)\end{array}$ & $\begin{array}{c}1.28 \\
(0.91-2.03)\end{array}$ \\
\hline TLR-4 & 1 & $\begin{array}{c}1.15 \\
(0.85-1.55)\end{array}$ & $\begin{array}{c}1.79 \\
(1.23-2.60)\end{array}$ & $\begin{array}{c}1.91 \\
(1.42-2.56)\end{array}$ & $\begin{array}{c}1.67 \\
(1.29-2.15)\end{array}$ \\
\hline TNF- $\alpha(\mathrm{pg} / \mathrm{mL})$ & $\begin{array}{c}3.7 \\
(1.5-9.1)\end{array}$ & $\begin{array}{c}5.1 \\
(3.0-8.8)\end{array}$ & $\begin{array}{c}5.1 \\
(3.6-7.4)\end{array}$ & $\begin{array}{c}4.0 \\
(2.0-7.8)\end{array}$ & $\begin{array}{c}3.8 \\
(2.0-7.1)\end{array}$ \\
\hline IL-6 (pg/mL) & $\begin{array}{c}5.0 \\
(1.2-20.8)\end{array}$ & $\begin{array}{c}22.0 \\
(11.9-40.6)\end{array}$ & $\begin{array}{c}87.3 \\
(63.2-120.7)\end{array}$ & $\begin{array}{c}83.0 \\
(44.8-153.8)\end{array}$ & $\begin{array}{c}31.9 \\
(18.1-56.1)\end{array}$ \\
\hline
\end{tabular}

$C P B$, Cardiopulmonary bypass; $X C$, crossclamp removal; $T L R$, toll-like receptor; $T N F$, tumor necrosis factor; $I L$, interleukin.

such ligand is the lipopolysaccharide component of gram-negative bacterial cell walls. TLR signaling stimulates host cytokine gene expression, thus propagating the inflammatory response and providing the molecular link between innate and adaptive immunity. ${ }^{5}$

It has been recently suggested that the innate immune system might play a similar role in initiating SIRS to noninfectious stimuli, and our findings concur with those of a previous investigation in adults undergoing coronary surgery. ${ }^{3}$ The nature of the ligands that stimulate increased TLR expression in the current setting is not fully understood. Possible candidates include heat shock pro- teins 60 and 70, so-called endogenous ligands that are released in response to ischemia, stress, and tissue necrosis. ${ }^{3}$ Further studies will address these issues in more detail.

\section{Conclusion}

SIRS in young children after CPB is associated with activation of the innate immune response. Future therapeutic strategies targeted at the innate immune response might be useful in preventing bypass-associated SIRS. 


\section{References}

1. Brix-Christensen V. The systemic inflammatory response after cardiac surgery with cardiopulmonary bypass in children. Acta Anaesthesiol Scand. 2001;45:671-9.

2. Lien E, Means TK, Heine H, Yoshimura A, Kusumoto S, Fukase K, et al. Toll-like receptor 4 imparts ligand-specific recognition of bacterial lipopolysaccharide. J Clin Invest. 2000;105:497-504.

3. Dybdahl B, Wahba A, Lien E, Flo TH, Waage A, Qureshi N, et al.
Inflammatory response after open heart surgery: release of heat-shock protein 70 and signaling through toll-like receptor-4. Circulation. 2002; 105:685-90.

4. Riordan SM, Skinner N, Nagree A, McCallum H, McIver CJ, Kurtovic $\mathrm{J}$, et al. Peripheral blood mononuclear cell expression of toll-like receptors and relation to cytokine levels in cirrhosis. Hepatology. 2003; 37:1154-64

5. Zhang G, Ghosh S. Toll-like receptor-mediated NF-kappaB activation: a phylogenetically conserved paradigm in innate immunity. $J$ Clin Invest. 2001;107:13-9.

\section{Modified minimally invasive coronary artery bypass after radical treatment for left breast cancer}

Toshiya Ohtsuka, MD, Mikio Ninomiya, MD, Takahiro Nonaka, MD, and Taisei Maemura, MD, Tokyo, Japan

$\mathrm{M}$ inimally invasive coronary artery bypass (MICAB) customarily means off-pump coronary artery bypass with a limited approach and is generally performed through a left anterior small thoracotomy by using the internal thoracic artery (ITA). ${ }^{1}$ This communication describes a modified MICAB technique with a video-assisted left subcostal approach, in which the left anterior descending artery (LAD) was revascularized with a saphenous vein (SV) graft by using an inflow from the right axillary artery. This procedure was applied to a female octogenarian who had undergone a radical left mastectomy and adjunctive radiation therapy for advanced left breast cancer.

\section{Methods}

An 81-year-old woman presented with unstable angina caused by an LAD lesion for which surgical intervention was indicated. Twenty years before, the patient had undergone a left mastectomy and extensive left axillary lymph node dissection because of advanced left breast carcinoma. The soft tissue component (adipose tissue and muscle) over the sternum and the left anterior bony structures had been completely removed, and the resulting skin defect over the midsternum and the left breast had been repaired by means of autograft implantation (Figure 1). Thereafter, adjunctive radiation therapy had been performed over both ITAs and the dissected left axillary area. Although there had been no cancer recurrence over the following 2 decades, ulceration had occurred

From the Department of Cardiovascular Surgery, Tokyo Metropolitan Fuchu General Hospital, Tokyo, Japan.

Received for publication Oct 15, 2003; revisions requested Nov 5, 2003; accepted for publication Nov 10, 2003.

Address for reprints: Toshiya Ohtsuka, MD, 2-9-2 Musashidai, Fuchu-shi, Tokyo 183-0042, Japan (E-mail: ootsuka-cvs@fuchu-hp.fuchu.tokyo.jp).

J Thorac Cardiovasc Surg 2004;127:1525-7

$0022-5223 / \$ 30.00$

Copyright $\odot 2004$ by The American Association for Thoracic Surgery

doi:10.1016/j.jtcvs.2003.11.053

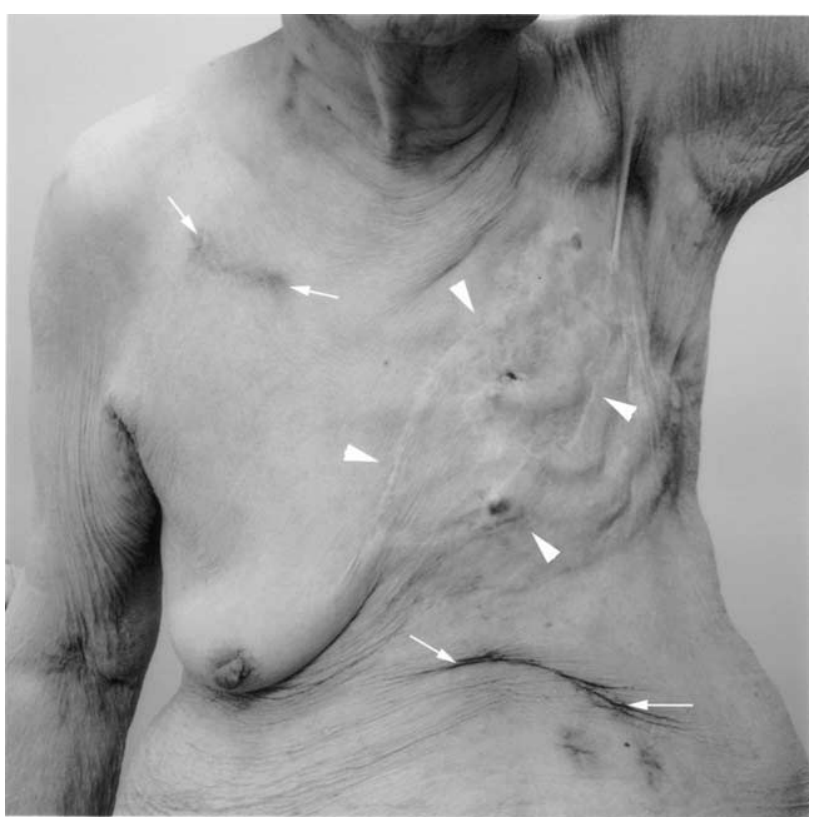

Figure 1. Photograph of patient's chest showing right subclavicular $(4 \mathrm{~cm})$ and left subcostal $(6 \mathrm{~cm})$ skin incisions (arrows) and auto-skin graft over sternum and left breast (arrowheads).

repeatedly on the ischemic skin over the thin chest wall, and therefore the left anterior small thoracotomy and sternotomy approaches were inapplicable. Furthermore, angiography showed that both irradiated ITAs were very small and that the left axillary artery, which lay in the extensively dissected and irradiated region, was inappropriate as an inflow for the bypass graft.

The patient was placed in the supine position, and general anesthesia was obtained through a single-lumen endotracheal tube. A 6-cm left subcostal skin incision was made parallel to the costal arch (Figure 1), and the left abdominal rectal muscle and the left anterior part of the diaphragm were divided. The pericardium was opened, and the mid-LAD was exposed, retracting the left costal 